\title{
Mental illness and legal discrimination
}

\section{Tony Zigmond}

Consultant Psychiatrist, Leeds Partnerships NHS Foundation Trust, Leeds, UK, email Anthony.Zigmond@leedspft.nhs.uk

W hy do so many countries have a mental health act? What is it about mental disorders which warrants that people who suffer from them be subject to different laws from the rest of society? The issues of stigma and discrimination against people with a mental disorder have moved up the agenda in many parts of the world. So why persist with a legal framework for the non-consensual medical treatment of those who are mentally ill which is different from that for those who are physically ill?

In 2002, in a court judgement, Dame Elizabeth ButlerSloss, one of the most senior judges in England, said:

A competent patient has an absolute right to refuse to consent to medical treatment for any reason, rational or irrational, or for no reason at all, even when that decision may lead to his or her death. (Re $B$ (adult: refusal of medical treatment), 2002)

But she was wrong. A competent adult, in England and Wales, may be detained in hospital and forcibly treated, for a mental illness, against the patient's capacitous wishes.

The law in England and Wales, in relation to an adult with a physical illness, is set out in the Mental Capacity Act 2005:

O The doctor, or other health professional, must gain the consent of an adult patient, if that person retains decisionmaking capacity, before examining or carrying out any procedure on that patient. If the doctor performs a medical procedure without the patient's consent, it is a criminal assault and a civil trespass (the doctor can be charged with an offence by the police and sued for compensation by the patient).

O The doctor must start by presuming the patient has capacity, unless there is evidence to the contrary.

O If the patient lacks capacity, then the doctor has to act in the patient's 'best interest'. Lack of capacity means the patient has an impairment of, or a disturbance in the functioning of, the mind or brain and is unable to understand the information relevant to the decision, to retain that information, to use or weigh that information as part of the process of making the decision, or is unable to communicate the decision, or fails to make the decision.

The lack of capacity is both time and decision specific.

O In determining what is in the patient's 'best interest', account must be taken of any previous wishes the patient has expressed, if known.

O An advance decision to refuse treatment, made by the patient when capacitous, must be honoured (because a capacitous person's refusal to accept treatment must be honoured). Advance requests for treatment should be given due consideration but are not binding (because a capacitous person's request for treatment does not place an obligation on the doctor).
O Adults may, if they wish, give another adult the authority to consent to, or decline, future medical treatment should the patient lose the capacity to make the decision.

O No matter what risks people may present to themselves or others, they cannot normally be deprived of their liberty unless they have been charged with, or convicted of, a crime. They can only be restrained for brief periods to prevent imminent serious danger. The degree of any restraint must be proportionate to the risks.

These rules exist because of the importance attached to the autonomy of the individual.

What are the equivalent provisions if the patient is given a diagnosis which sits in the 'mental and behavioural disorders' chapters of the International Classification of Diseases? That is, what are the rules for the non-consensual detention and treatment of a person with a mental illness? For England and Wales, the Mental Health Act 1983 says that a person may be detained if he or she:

is suffering from mental disorder of a nature or degree which warrants the detention of the patient in a hospital for assessment (or for assessment followed by medical treatment) for at least a limited period; and he ought to be so detained in the interests of his own health or safety or with a view to the protection of other persons.

There is no suggestion that patients should be unable to make the decision for themselves. It is solely based on risk. In relation to treatment for a mental disorder, patients can be forced to have treatment they do not want, because the doctors think it is in their best interest, even when patients say it is not and retain the capacity to make that decision and the only risk is to their own health. Advance refusals of treatment are not honoured.

This, as explained above, is not permitted in relation to treatment for physical illness. Oddly, it is the disorder that is to be treated which determines whether or not the capacitous adult retains autonomy, not the person's mental state.

Imagine two people, one with schizophrenia and one with cancer. In both cases it is clear that they are able to make rational judgements about their treatment. They both recognise that they are ill and that their illness can be treated and that there are consequences to not receiving treatment. In the case of the former, the fact that he has capacity has no relevance and even if fully capable his unwillingness to consent can be overridden. In the case of the latter, it is central, and for treatment to proceed without the consent of this person with capacity would be an assault. If the patient with schizophrenia also has cancer, and retains decisionmaking capacity, he is entitled to refuse treatment for the cancer - but not for the schizophrenia.

The Mental Health Act for England and Wales is perhaps unusual in taking no account of patients' ability to make decisions for themselves. The equivalent Scottish act, the 
Mental Health (Care and Treatment) (Scotland) Act 2003, does require some impairment of decision making - 'because of the mental disorder, the patient's ability to make decisions about the provision of medical treatment is significantly impaired' - but does not require that the person lacks the capacity to make the relevant decision in the way that is required for adults suffering from physical illnesses.

For patients in both jurisdictions, total control of the patient, including deprivation of liberty, is authorised if the criteria for detention are met. The authority is not limited to providing care and treatment solely in relation to the specific decision about which the patient is incapacitous.

The Irish Mental Health Act 2001 includes a similar requirement:

because of the severity of the illness, disability or dementia, the judgment of the person concerned is so impaired that failure to admit the person to an approved centre would be likely to lead to a serious deterioration in his or her condition or would prevent the administration of appropriate treatment that could be given only by such admission.

The Irish act also makes reference to 'best interests' but it is qualified:

In making a decision under this Act concerning the care or treatment of a person (including a decision to make an admission order in relation to a person), the best interests of the person shall be the principal consideration with due regard being given to the interests of other persons who may be at risk of serious harm if the decision is not made.

In New Zealand, the Mental Health (Compulsory Assessment and Treatment) Act 1992 requires that the disorder either causes a 'serious danger to the health or safety of that person or of others' or 'seriously diminishes the capacity of that person to take care of himself or herself'. This is similar to the law in Queensland, Australia (Mental Health Act 2000), which states that the person must either 'lack the capacity to consent to be treated for the illness' or 'has unreasonably refused proposed treatment for the illness'.

The mental health acts that make provision for compulsory treatment in the community tend to have a similar lack of regard for patient autonomy. A rare exception is from Canada, where the criteria for a community treatment order set out in Saskatchewan's Mental Health Services Act 2006 include the following:

The person is unable to understand and to make an informed decision regarding his or her need for treatment, care or supervision as a result of the mental disorder.

Ontario has a similar criterion: the person 'has shown or is showing a lack of competence to care for himself or herself' while living in the community,

It is not only nationally that the legal framework for the non-consensual care and treatment of people with a mental illness differs from the framework that applies to people who are physically ill. Article 5 of the European Convention on Human Rights (1950) is highly discriminatory. It groups together those of unsound mind, drug addicts, alcoholics and vagrants, as people who may legitimately be locked up, without any requirement that they have committed an offence or are incapable of making decisions for themselves, or even that they will personally benefit from the intervention.

The United Nations (UN) starts better with its Declaration of Human Rights (1948):

Recognition of the inherent dignity and of the equal and inalienable rights of all members of the human family is the foundation of freedom, justice and peace in the world.

Unfortunately, while it does better than most, it fails to maintain this high ideal. The UN Principles for the Protection of Persons with Mental Illness and the Improvement of Mental Health Care (UN General Assembly Resolution 46/119 of 17 December 1991) set out the grounds for compulsion:

O that, because of the mental illness, there is a serious likelihood of immediate or imminent harm to that person or to other persons; or

o that, in the case of a person whose mental illness is severe and whose judgement is impaired, failure to admit or retain that person is likely to lead to a serious deterioration in his or her condition or will prevent the giving of appropriate treatment that can be given only by admission to a mental health facility in accordance with the principle of the least restrictive alternative.

I return to where I started. Why? Why do people who are mentally ill need a different legal framework for their nonconsensual care and treatment?

\section{Reproductive risk to maternal mental health: international perspectives}

\section{David Skuse}

Behavioural and Brain Sciences Unit, Institute of Child Health, London WC1N 1EH, UK, email dskuse@ich.ucl.ac.uk

D espite the emphasis placed, in international comparisons of obstetric management, on the perinatal mortality rate as a measure of excellence of care (or otherwise), there has been relatively little discussion of the impact of birth on maternal mental health. When thinking about this issue, we need to consider both the mental state of the mother during the antenatal period as well as the subsequent impact of the birth on her mood and risk of major mental illness. According to the authors contributing to the theme discussed here, that risk is much higher 